\title{
Post Operative Infective Morbidity in Gynaecological and Obstetrical Surgeries at KMCTH
}

\author{
Meena Thapa,. Nira S. Shrestha. Nitin Bhandari, \\ Chanda Karki, Saraswati M. Padhye. \\ Dept Obs / Gyn KMCTH
}

\begin{abstract}
Aim: To determine infective morbidity in post-operative cases of major Gynaecological and obstetrical surgeries.

Methods: This was prospective hospital based study carried out among patients who underwent major gynecological and obstetrical surgeries at KMCTH. Patients with preexisting infection were not included in the study. This study was carried out over 2 month period from $1^{\text {st }}$ December 2009 to $31^{\text {st }}$ Jan 2010, where follow up ended on $4^{\text {th }}$ February 2010. All patients had received antibiotics for 5 days postoperatively. The patients were followed up daily with 6 hourly temperature charting, daily physical examination, and urine routine/culture examination at removal of Foley catheter. The wound inspection was done on $3^{\text {rd }}$ day of surgery.
\end{abstract}

Results: Total of 123 patients were enrolled in the study, of which, $73(59 \%)$ cases were obstetrical and 50 (41\%) cases were gynaecological, 4 (3.25\%) patients had febrile morbidity, 2 in gynaecological and 2 in obstetrical cases. 1 (0.8\%) patient of lower segment caesarean section (LSCS) had developed surgical site infection (SSI) which required resuturing of wound.

Conclusion: Commonest post operative infective morbidity following major gynaecological and obstetrical surgeries is febrile morbidity.

Keywords: Infective morbidity, febrile morbidity, surgical site infection

\section{Introduction}

Infection is the major complication during post operative period following major gynaecological and Obstetrical surgery, which is most often caused by over growth of the diverse bacterial flora. The bacteria invade the tissue and makes it vulnerable to infection due to placement of foreign body like suture, or catheter. Infection during post operative period may present with febrile illness. Fever may be due to infection of urinary tract, respiratory tract, wound infection and deep vein thrombosis occasionally, due to peritonitis.

Febrile morbidity during post operative period is defined as the rise of temperature $\geq 100.4^{\circ} \mathrm{F}$ (38 ${ }^{\circ} \mathrm{C}$ ) after 24 hours of surgery and which should be recorded twice 4-6 hours apart ${ }^{1}$. The wound infection following elective gynaecological surgery varies from 2.1 to $3.5 \%{ }^{1}$. Likewise, Urinary Tract Infection becomes the major post operative infection following vaginal surgery ${ }^{2}$. The risk of bacteriuria develops in approximately $1-2 \%$ following catheterization ${ }^{3}$.In very few cases, pelvic abscess and peritonitis may complicate the post operative process of surgery. Fortunately, use of prophylactic antibiotic in surgery reduces the frequency and severity of infective complication. This study was carried out to determine post operative infective morbidity like febrile morbidity, urinary tract infection, wound infection and chest infection in patients who underwent gynaecological and Obstetrical Surgery.

\section{Methods}

This is a prospective analytical study. It was conducted at obs/gyn department of Kathmandu Medical College

Correspondence

Dr.MeenaThapa

Asst. Prof.

Dept Obs / Gyn

Kathmandu Medical College, Teaching Hospital

Mobile : 9851060052

Email : menathapa513@hotmail.com, 
Teaching Hospital over the period of 2 month, from $1^{\text {st }}$ December 2009 to $31^{\text {st }}$ January 2010 while, followup of cases were completed on $4^{\text {th }}$ February 2010. The Patients who underwent major gynaecological and obstetrical surgeries were included in the study. The patients with infection like fever, abnormal urine reports, or who were on antibiotics before surgery were excluded from the study.

Total of 123 patients were included in the study. All of them had received antibiotic prophylactic for 5 days post operatively. They had indwelling catheter for 24 to 48 hours after surgery.

The patients were evaluated daily after surgery, until the day of discharge; to investigate development of any complication. The patients were evaluated every day for fever and chest infection. Daily 6 hourly temperatures were recorded with standard mercury thermometer.

Chest infection was suspected in patients with chest pain and cough. All patients were evaluated in detail so as not to miss any signs of chest infection. The patients with suspected chest infection were further evaluated with chest $\mathrm{X}$-ray. Urine routine examination and culture were sent for every patient after removal of Foley catheter and reports were evaluated for urinary tract infection.

Surgical wound site inspection was done on $3^{\text {rd }}$ day of surgery. Wound indurations, discharge from wound, wound gaping were considered as surgical site infection (SSI). Patients with discharge from wound and wound gaping were further evaluated with wound swab culture.

\section{Results}

During the period of 2 months 123 patients were included in the study that underwent major gynaecology and obstetric surgeries. Of the total cases 73 cases (59\%) were Obstetrical cases and 50 cases (41\%) were gynaecological cases. Among 73 Obstetrical surgery $20.5 \%$ were elective and rest were emergency. Similarly among the gynaecological surgery $90 \%$ were elective.

\section{Fig 1. Type of surgery}

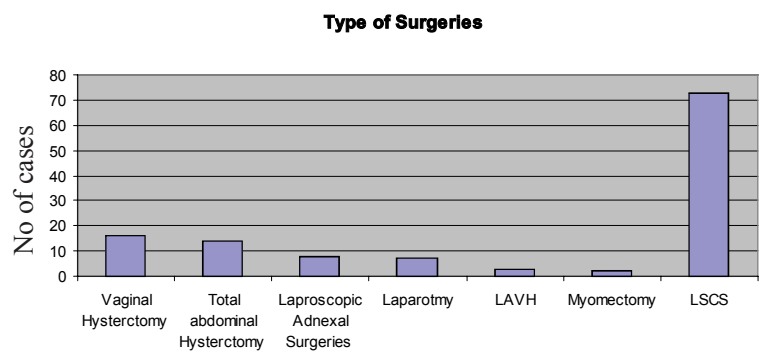

Table 1. Post operative complication

\begin{tabular}{lcccc}
\hline Surgery & $\begin{array}{c}\text { FM } \\
(\mathbf{n}=\mathbf{4})\end{array}$ & $\begin{array}{c}\text { UTI } \\
(\mathbf{n}=\mathbf{1})\end{array}$ & $\begin{array}{c}\text { WI } \\
(\mathbf{n}=\mathbf{1})\end{array}$ & Total \\
\hline $\begin{array}{l}\text { Gynaecological }(\mathrm{n}=50) \\
\text { surgery }\end{array}$ & 2 & 1 & 0 & 3 \\
$\begin{array}{l}\text { Obstetrical }(\mathrm{n}=73) \\
\text { Surgery }\end{array}$ & 2 & 0 & 1 & 3 \\
\hline & FM & $=$ & Febrile Morbidity \\
UTI & $=$ & Urinary Tract Infection \\
WI & $=$ & Wound Infection
\end{tabular}

Out of 123 patients 4 (3.2\%) had febrile morbidity, of which 2 were in gynaecological surgery and 2 were in obstetrical surgery. Urinary Tract Infection was seen in 1 case of gynaecological surgery, but it was not seen in obstetrical cases. Only 1 case of wound infection was found in obstetrical surgery. No case of chest infection had occurred during study period. Overall infective morbidity was found in 6 cases $(4.9 \%)$. Fever was not seen in cases with Urinary Tract Infection and wound infection.

\section{Discussion}

Overall infective morbidity during post operative period was seen in $4.9 \%(6 / 123)$ cases of surgeries. Wound infection was seen in $1(<1 \%)$ case of elective caesarean section which required secondary resuturing. Staphylococcus aureus was grown in that wound. Reports from the various centers had shown up to $10 \%$ of cases wound infection ${ }^{4}$.

Saha et $\mathrm{al} \mathrm{l}^{5}$ had studied 50 cases of hysterectomy at $\mathrm{KMCTH}$. She found $6 \%$ wound infection in her study but compared to her wound infection was very less in our study $(<1 \%)$. Wound infection after hysterectomy was reported $8.6 \%$ by Taylor ${ }^{6}$. Consulo studied 88 wound swab culture from abdominal hysterectomy, he reported $61.3 \%$ culture positive cases but no cases of wound infection was found in abdominal hysterectomy in our study. In Spain Ecoli, Staphylocococcus aureus and Mycoplasma hominis were common pathogens for wound infection following hysterectomy ${ }^{7}$.

Urinary bacteria growth was seen only in $1(<1 \%)$ case of gynaecological surgery. Routine urinary examination showed abnormal finding in another 3 cases but bacterial growth did not occur in those cases. Ojha ${ }^{8}$ from TUTH had reported higher incidence of Urinary Tract Infection. She had analyzed 316 gynaecological and Obstetrical case records for bacterial growth in urine according to duration of catheterization. She reported $46 \%$ positive urinary bacterial growth in both gynaecolgical and Obstetrical surgery. Similar Incidence of urinary tract infection (40\%) was reported by Kingdom ${ }^{9}$. 
Febrile morbidity was seen only in $3.2 \%$ cases in our study. It was reported higher in studies from Netherland and Wales (6.5\%- $12.5 \%$ ) but study from $\mathrm{KMCTH}$ reported only $2 \%$ febrile morbidity following hysterectomy ${ }^{5,10}$.

\section{Conclusion}

To conclude infective morbidity, including febrile morbidity, UTI and wound infection is very less following gynaecological and obstetrical surgeries irrespective of elective or emergency surgery. Febrile morbidity is commonly encountered morbidity during post operative period.

\section{References}

1. Rock J A, Jones H W III. "Postoperative Infections: Prevention and management " Te Linde's Operative Gynecology $9^{\text {th }}$ Edition, Lippincott Williams and Wilkins 2003; 195208

2. Hegemeier T, Retzke U, Liebetrau B. “ Micturation and incidience of post operative urinary tract infection in surgical gynaecology" Zeutralbl Gynakok 1991; 113 (20): 1107 -13

3. Agrawal A, Dwivedi S, Manju M, Ahmed GN. "Catheter-associated urinary tract infection: Concept and management" Obs \& Gynae Today 2005; 10(11): 650-654

4. Hemsell D L, Johnson E R, Hemsell P G, Brenda
J. Nobles and Molly C. Heard. "Cefazolin for Hysterectomy Prophylaxis" Obstetrics and Gynaecology 1990 Oct; 76 ( 4) : 603-606

5. Saha R, Sharma M, Padhye S, Karki U, Pandey S, Thapa J. "Hysterectomy: An analysis of perioperative and post operative complication" KUMJ 2003; 1(2): 124-127

6. Tylor G, Herrick T. Wound infection after Hysterectomy Opportunities for practice improvement Am J. of Infection Control 1998 June; 26: 254-57

7. Miranda C, AladosJ C. "Post- Hysterectomy wounds infection a review: Diagnostic Microbiology and Infectious disease 1993 July; 17(1): 41-44

8. Ojha N. "Bacteriruia following Foley catheterization after Gynaecological and obstetrical surgery" NJOG 2008; 3 (1): 35-38.

9. Kingdom JC, Kitchener HC, Maclean AB. "Post operative urinary tract infection in Gynecology Implications for an Antibiotic prophylaxis policy" Obstet Gynecol 1990 Oct; 76(4): 636-8

10. Brown E M, Depares, Robertson A A, Jones S, Hughes A B, Coler E C, Morgan J R. "Amoxycillin Clavulanic Acid (Augmentin) Versus Metronidazole as Prophylaxis in Hysterectomy: A prospective, Randomized Clinical Trial" British Journal of Obs and Gyn 1988 March; 95:286-293 